\title{
Tecnologia e Educação: quais os desafios?
}

\section{Technology and Education: what are the challenges?}

Luís Miguel Dias Caetano* Universidade do Estado do Rio Grande do Norte

Resumo Nos últimos anos temos assistido a um enorme investimento em recursos tecnológicos na educação. É internacionalmente reconhecido que Portugal ocupa uns dos primeiros lugares europeus em termos de disponibilização de tecnologias nas escolas. Contudo, são muitas as vozes que colocam algumas dúvidas sobre a eficácia e eficiência desses investimentos. No momento de avaliar os projetos tecnológicos, são encontrados com alguma frequência, falhas ao nível da formação de professores e nas metodologias com que esses recursos são utilizados. Este artigo visa compreender o verdadeiro papel da tecnologia na educação e apresentar algumas orientações para que a sua integração aconteça com maior intencionalidade educativa.

PALAVRAS-ChAVE: Tecnologia; Aprendizagem; Competências tecnológicas.

Abstract We have seen a huge investment in technological resources in education recently. It is internationally recognized that Portugal is one of the European leaders in making technology accessible to schools. However, there is doubt in regards to the effectiveness and efficiency of these investments. When evaluating technological projects, problems in teachers' education and in the methodologies are often found.This paper aims to provide a better understanding about the true role of technology in education and also to present some guidance so that its integration can occur within a higher level of educational intentionality.

KEYWORDS: Technology; Learning; Technological competences. 


\section{Tecnologia e Aprendizagem}

Um dos campos mais férteis para o uso da tecnologia é o da Educação. A tecnologia, tem vindo a potenciar novas situações de aprendizagem, e esse facto tem sido acompanhado por um número crescente de publicações e estudos, mas o atraso na implementação e apropriação de várias metodologias e ferramentas, tem revelado um atraso nas mudanças desejadas. Entre outros motivos, podem apontar-se o fato da integração da tecnologia não respeitar o meio social dos alunos e os seus conhecimentos prévios e de alguns programas de computador não permitirem a colaboração dos alunos e professores (SOUZA, 2005).

A introdução das tecnologias na Educação não pode ser considerada apenas como uma mudança tecnológica. Não se trata simplesmente de substituir o quadro preto ou o livro pelo ecrã do computador. A introdução das tecnologias na Educação pode estar associada à mudança do modo como se aprende, à mudança das formas de interacção entre quem aprende e quem ensina, à mudança do modo como se reflecte sobre a natureza do conhecimento (TEODORO, 2008).

Importa, assim, realizar uma breve análise às teorias de aprendizagem e à sua aplicação em contextos tecnológicos.

Antes de mais, convém encontrar uma definição de aprendizagem que, apesar de poder assumir várias evoluções, âmbitos e definições (MAYER, 1992; BELTRÁN, 1996; OLIVEIRA, 2007), optámos por entender que se traduz num processo que produz mudança no comportamento ou na capacidade do sujeito (OLIVEIRA, 2007).

As teorias comportamentalistas centram-se no facto de que a aprendizagem ocorre como uma mudança de comportamento. São estudadas as respostas dadas pelo sujeito aos estímulos fornecidos pelo ambiente externo, não levando em consideração o que ocorre na sua mente durante o processo de aprendizagem (OLIVEIRA, 2007).

As teorias comportamentalistas, como seria de esperar, interessaram-se desde logo pelo potencial instrutivo dos recursos tecnológicos. Baseadas num princípio bastante simples - a um estímulo externo - o organismo reage e a aprendizagem nada mais é do que um refinar progressivo das acções do sujeito pelas consequências dos seus actos - os novos recursos tecnológicos constituíam fontes adicionais de estímulos a ministrar ao sujeito (COUTINHO, 2006).

Nestes casos, os alunos não tomam consciência entre causa e efeito, podendo contribuir para situações de aprendizagem sem motivação (SERRA, 1986).

Esta teoria está ainda hoje bem presente em vários recursos tecnológicos que promovem a repetição de comportamentos, apresentando para cada interacção, uma resposta ou estímulo.

Por sua vez, as teorias cognitivistas assumem que a aprendizagem produzse a partir da experiência, que não é entendida como uma simples transferência, mas 
como uma representação da mesma. A ênfase é colocada na forma como se adquirem as representações do mundo, como se armazenam na memória ou estrutura cognitiva. É, assim, realçado o papel da memória, não no sentido tradicional que a afastava da compreensão, mas antes como um valor construtivista (SILVA, 2004), por outras palavras, a aprendizagem consiste na construção do conhecimento.

O objectivo principal do ensino é promover a compreensão geral de uma matéria e, quando o aluno compreende a estrutura de um assunto ou de uma matéria, vê-a como um todo relacionado. A formação de conceitos globais e a construção de generalizações coerentes são fundamentais durante o processo de aprendizagem (SPRINTHALL \& SPRINTHALL, 1993).

Enquadrado nestas teorias cognitivas estão os recursos tecnológicos que, por exemplo, contenham actividades onde os temas possam ser apresentados e organizados facilmente a qualquer aluno.

Por fim, as Teorias Construtivistas encaram a aprendizagem como o resultado de uma construção mental, em que os alunos aprendem ajustando a nova informação à anteriormente existente e onde a aprendizagem é também afectada pelo contexto, pelas crenças e pelas atitudes (OLIVEIRA, 2007).

Em referência às teorias construtivistas, teorizou-se assim que o melhor da nossa aprendizagem era a que fosse construída por cada um de nós, no nosso próprio trajecto, onde íamos descobrindo, assimilando e adaptando às nossas estruturas, transformando-as. Desse modo, qualquer criança através, por exemplo, do computador pode seguir um trajecto tendo como referência um guião elaborado pelo professor e evoluindo para o seu próprio caminho. Para esse efeito, a criança pode receber uma história inacabada, o esboço ou parte de um desenho, alguns passos já dados para resolver um problema, etc. O professor deixa de ser o centro do conhecimento e centra a actividade no aluno, funcionando como o facilitador e o orientador (FERNANDES, 2004).

Para Ramos (2005), para além da perspectiva construtivista que parece ganhar expressão com determinadas estratégias de utilização das tecnologias existem outras perspectivas que estão em desenvolvimento, como é o caso do construtivismo colaborativo. Para o autor, esta forma de construtivismo pode ser encarada como uma exploração pedagógica das tecnologias, onde os alunos não só aprendem através dos processos de construção do próprio conhecimento no seu contexto e na construção pessoal do significado, aprendem ainda por interacções sociais emergentes no contexto de aprendizagem como também em situações de envolvimento activo nos processos de construção do conhecimento para os outros.

Ramos (2005) resume esta definição no facto de se aprender com os outros e aprender para os outros, rompendo os limites convencionais da aprendizagem e do currículo. 


\section{Podemos assim sumariar que:}

- As Teorias Comportamentalistas apontam para a utilização de recursos tecnológicos que promovam actividades de natureza mais individual e sem promoção de processos de reflexão;

- As Teorias Cognitivitas apontam para a utilização de recursos tecnológicos que promovam actividades que convidem os alunos a uma análise de alguns elementos;

- As Teorias Construtivistas apontam para a utilização de recursos tecnológicos que promovam actividades abertas levando os alunos a um maior esforço de análise, reflexão individual ou em grupo para construir o seu conhecimento.

Julgamos que o grande desafio não está na escolha preferencial de uma ou outra teoria, mas sim num diagnóstico rigoroso das situações de aprendizagem, na concepção de programas e na utilização de didácticas adequadas.

Para Fernandes (2004), necessitamos então de operacionalizar o conhecimento e a aprendizagem em recursos tecnológicos que permitam:

- Aprender à medida das necessidades e em função dos conhecimentos possuídos;

- Reduzir o tempo de aprendizagem, para aumentar o fluxo de conhecimentos;

- Criar modelos em consonância com as características pessoais e da matéria;

- Construir métodos geradores de motivação, de persistência e de responsabilidade;

- Elaborar programas multimédia que unifiquem os estímulos (som, imagem e acção psicomotora) e dêem eficácia ao acto de aprender;

- Conceber métodos de formação contínua e de reconversão, que permitam a eficácia do sistema e a mudança de funções em tempo útil;

- Conceber uma escola também com base no princípio do prazer e não só com base no princípio da realidade.

\section{Vantagens de utilização da tecnologia na sala de aula}

Todos os países desejam melhorar a qualidade e eficácia da aprendizagem escolar, apostando nas tecnologias como um meio para conseguir (OCDE, 2001). Num relatório sobre os desafios das tecnologias na educação, a OCDE (2001) distingue três séries de argumentos para incluir as tecnologias em contexto educativo: económicos, sociais e pedagógicos.

No argumento económico, estão elementos relacionados com a evolução da economia mundial que valoriza a dimensão tecnológica e onde o conhecimento tecnológico é sempre potenciador de fácil integração no mercado de trabalho. Tendo esta consciência da evolução da economia mundial, os alunos podem ter um motivo adicional para a aprendizagem mediada pela tecnologia. 
Os argumentos sociais contemplam a capacidade de manusear as tecnologias como requisito essencial para participar na sociedade, revelando-se tão fundamental como a leitura e o cálculo. Neste argumento social, cabe a designação de alfabetização digital que acaba por abarcar um vasto leque de competências e processos que as tecnologias fomentam e que se convertem num requisito e direito para os alunos.

Por fim, os argumentos pedagógicos centram-se no papel das tecnologias no processo de ensino e aprendizagem. As tecnologias podem aumentar e enriquecer a aprendizagem graças à actualidade e realismo que os actuais recursos apresentam. A experiência da OCDE (2001) aponta para o facto dos alunos revelarem desinteresse pela escola quando esta não lhes oferece ambientes e experiências tecnológicas.

Cruz (2009) aponta três conjuntos de fundamentos para a integração curricular das tecnologias:

- Do ponto de vista da aprendizagem: considerando as principais teorias da aprendizagem que têm vindo a influenciar a utilização educativa das tecnologias em contexto educativo;

- Do ponto de vista da sociedade: considerando os dados que criam exigências ao nível da selecção de conteúdos adequados aos interesses dos cidadãos;

- Do ponto de vista da investigação: perspectivando os dados que nos permitam clarificar as perspectivas teóricas subjacentes à utilização das TIC (Tecnologias de Informação e Comunicação) ao serviço da aprendizagem escolar, bem como os benefícios decorrentes dessa utilização.

Ponte (2002) aponta como vantagens de integração das tecnologias na educação o facto de permitirem o acesso à informação, permitirem a produção de informação, serem um excelente meio de comunicação à distância, uma ferramenta para o trabalho colaborativo e promoverem formas de interacção social.

Para Paiva (2002), as tecnologias são uma mais-valia para o processo educativo permitindo:

- Ganhar tempo nas tarefas rotineiras;

- Ter a formação à distância com participação em trabalhos e experiências conjuntas à escala nacional e internacional;

- Interagir de forma diferenciada entre professor e alunos;

- Realizar pesquisa online dirigida;

- Comunicar por e-mail.

Um estudo sobre o impacto das tecnologias nas escolas europeias (BALANSKAT, BLAMIRE \& KEFALA, 2006) refere que:

- As tecnologias têm um impacto positivo no desempenho escolar;

- Alunos, professores e pais consideram que as tecnologias têm um impacto positivo sobre a aprendizagem dos alunos; 
- A utilização das tecnologias melhora os níveis de habilitações escolares de Inglês;

- As escolas que integram as tecnologias no seu currículo de forma dinâmica apresentam melhores resultados do que as escolas que não o fazem;

- Os melhores impactos (retornos) dos investimentos em tecnologia ocorrem em escolas com ambientes mais favoráveis à sua integração (cultura escolar, tipos de liderança, etc.);

- Os professores reconhecem que os alunos estão mais motivados e atentos quando os recursos tecnológicos são usados na sala de aula (LEMOS, 2011);

- Os alunos melhoram os seus comportamentos e o desenvolvimento de competências;

- As tecnologias favorecem a aprendizagem diferenciada que permite ir ao encontro das necessidades de cada aluno;

- As tecnologias favorecem igualmente a aprendizagem independente que é entendida como factor de autonomia e responsabilidade;

- As tecnologias promovem o trabalho em equipa e a colaboração entre alunos e entre professores;

- O sofware de qualidade que enriqueça a aprendizagem é também importante para o desenvolvimento.

Pelo conjunto de vantagens enumeradas, facilmente entendemos o seu potencial motivador que pode imprimir às aprendizagens. A ausência de motivação dos alunos é uma realidade com a qual os professores se deparam e que interfere na qualidade das aprendizagens. No entanto, as tecnologias podem contribuir para melhorar os níveis de motivação e a concentração dos alunos. Estudos de Lemos (2011) revelam que as tecnologias melhoram os níveis de concentração, de organização, do empenho, da participação e do interesse dos alunos pelo trabalho desenvolvido em sala de aula após a introdução das tecnologias.

A ideia que, por exemplo, os computadores promovem o isolamento social e reduzem a criatividade são dois mitos que Amante (2007) contraria. Para a autora, os computadores têm demonstrado ser promotores de interacção e do trabalho corporativo, criando oportunidades para o desenvolvimento de competências sociais e cognitivas. Além disso, rejeita a ideia de que a utilização dos computadores transforma as crianças em sujeitos passivos. A autora refere que mesmo quando se acusam os computadores de limitarem a criatividade das crianças, a primeira coisa que lhe ocorre é questionar se a escola, antes de existirem computadores, era criativa. De qualquer modo, Amante (2007) não tem dúvidas sobre o facto do computador poder ser usado de forma não criativa.

Para além do contributo das tecnologias na área dos comportamentos, Amante (2007) e Ramos (2007) reconhecem que as mesmas estimulam o desenvolvimento da linguagem, do pensamento matemático e que podem ter um bom contributo para a educação multicultural. 
Podemos ainda acrescentar mais dois tipos de vantagens pela integração das tecnologias na educação (COSTA \& JORGE, 2011):

- Desenvolvimento de competências relacionadas com a criatividade e inovação, com a autonomia e com o espírito de iniciativa;

- Ao nível da comunicação e colaboração, tendo em vista a superação de barreiras entre os diferentes intervenientes da comunidade educativa, seja entre os próprios docentes (isolamento profissional), seja entre escolas ou entre estas e o resto da comunidade educativa.

Um estudo de Rasinen (2003), que envolveu a comparação da forma como as tecnologias eram integradas no currículo de seis países (Austrália, Inglaterra, França, Países Baixos, Suécia e Estados Unidos), revelou que, onde o currículo é baseado numa lógica de que as pessoas enfrentam no dia-a-dia inúmeras situações com interacção com tecnologia. Desse modo, as competências adquiridas ao longo do processo educativo devem permitir que os alunos:

- Desenvolvam espírito crítico e aplicação de novas ideias;

- Encontrem soluções inovadoras para a comunidade;

- Consigam ligar com a incerteza;

- Possam cooperar entre si;

- Apreciem as diferenças culturais;

- Consigam aprender ao longo da vida;

- Conheçam várias redes de informação local, nacional e internacional.

Na sequência deste estudo de Rasinen (2003), julgamos que a grande vantagem de integração da tecnologia na educação é o desenvolvimento de múltiplas competências nos alunos que lhes permitam ser melhores cidadãos, não apenas ao nível da aquisição de conhecimentos escolares mas, sobretudo, na sua relação com o mundo.

Em suma e para que vejamos o enorme impacto que a tecnologia pode ter, desde que perfeitamente integrada na educação, é o facto do estudo do European Schoolnet (BALANSKAT, BLAMIRE \& KEFALA, 2006) revelar que, nos países da $\mathrm{OCDE}^{1}$ há uma associação positiva entre o tempo dedicado à utilização educativa da tecnologia e o desempenho dos alunos em testes de matemática do PISA ${ }^{2}$.

\section{Modalidades de utilização das tecnologias}

Um estudo realizado por Paiva (2002), junto de mil e seiscentos estabelecimentos das redes pública e privada, que teve como principal objectivo conhecer a utilização das tecnologias, nos contextos pessoal e educativo/pedagógico, pelo universo dos professores portugueses de todos os níveis de ensino à excepção do superior, revelou que, no caso dos professores, estes recorrem sobretudo à utilização das tecnologias para elaborar fichas e/ou testes, pesquisar na internet assuntos das disciplinas e para elaborar apresentações. Quando em interacção directa com os alunos, os professores usam, sobretudo, o processador de texto, programas gráficos/de desenho, folha de cálculo, E-mail, Internet e Software Pedagógico. 
À semelhança dos estudos de Paiva (2002) onde os professores fazem uma utilização mais individual das tecnologias, também Neto (2010) identifica que a maior parte dos professores usam as tecnologias mais frequentemente para uso pessoal do que para preparar materiais ou desenvolver actividades com os alunos.

$\mathrm{Na}$ sequência de um estudo sobre o impacto do Plano Tecnológico da Educação (LOPES, 2010), é reconhecido pelos professores que as tecnologias podem diversificar as actividades na sala de aula levando alguns professores a recorrerem à sua utilização nas seguintes situações:

- Para melhorar a relação de cooperação entre os alunos;

- Para recorrer a imagens para consolidar as aprendizagens;

- Para promover a motivação dos alunos;

- Para que os alunos tenham um comportamento mais activo nas aulas;

- Para desenvolver nos alunos competências ao nível da comunicação oral e escrita;

- Para promover uma aprendizagem mais autónoma pelos alunos.

Quando um professor realiza uma planificação de aula com utilização das tecnologias, deve entre outros aspectos, ter em consideração elementos de natureza organizativa, metodológica e formativa.

Cabero (2006) apresenta um conjunto de recomendações para cada um desses elementos, conforme está sintetizado no Quadro 1.

\begin{tabular}{|c|c|}
\hline $\begin{array}{c}\text { Tipologia de } \\
\text { Aspectos }\end{array}$ & Algumas Recomendações \\
\hline Organizativos & $\begin{array}{l}\text { - O trabalho com computadores deve ser feito em grupos reduzidos; } \\
\text { - O professor deve situar os computadores de forma que possa ver todos os } \\
\text { alunos e os respectivos monitores; } \\
\text { - Os recursos tecnológicos devem estar posicionados de forma a não } \\
\text { perturbar a fácil mobilidade de todos na sala de aula. }\end{array}$ \\
\hline Metodológicos & $\begin{array}{l}\text { - Preparar actividades que potencializem o trabalho em grupo; } \\
\text { - Distribuir o tempo das actividades de modo que todos os alunos consigam } \\
\text { trabalhar com os equipamentos; } \\
\text { - Preparar actividades suficientes para distribuir aos alunos que terminem } \\
\text { em primeiro lugar; } \\
\text { - Preparar actividades que desenvolvam a criatividade nos alunos. }\end{array}$ \\
\hline
\end{tabular}


Continuação quadro 1

\begin{tabular}{|l|l|}
\hline \multirow{3}{*}{ Formativos } & $\begin{array}{l}- \text { O professor deve familiarizar-se com os equipamentos e os softwares com } \\
\text { que os alunos vão interagir; }\end{array}$ \\
& - O professor deve conhecer os desenvolvimentos da tecnologia; \\
& $\begin{array}{l}\text { O professor deve conhecer os softwares educativos que vão sendo lançados } \\
\text { no mercado de forma a analisar suas potencialidades. }\end{array}$ \\
\hline
\end{tabular}

Quadro 1 - Aspectos a considerar na planificação de actividades com tecnologia

Em suma, mais do que a escolha dos recursos tecnológicos, importa que a sua escolha seja efectuada com intencionalidade educativa de modo a proporcionar situações enriquecidas de aprendizagem (RAMOS, 2005; DAMÁSIO, 2007; COSTA, 2008).

\section{O papel do professor na utilização educativa da tecnologia}

Com o desenvolvimento tecnológico em quase todos os sectores e, em particular, na educação, colocam-se novos desafios aos professores.

O papel do professor deverá, por isso, mudar, deixando de ser um simples transmissor de conhecimentos para assumir o papel de guiar o aluno, motivando-o e incutindo o sentido da investigação e criação (MODERNO, 1984), desempenhando assim um papel fundamental na integração das TIC no currículo escolar (UNESCO, 2004).

Um estudo ${ }^{3}$ da UNESCO revelou que o professor tem, através das tecnologias, um papel importante a desempenhar na mudança do ensino/aprendizagem de paradigma e, através da frequência de programas de formação de professores, deve concentrar-se menos em competências básicas de alfabetização e mais na utilização das TIC no ensino (Unesco, 2004).

Para Ponte e Serrazina (1998), os professores devem possuir, ao nível das tecnologias, as seguintes competências:

- O conhecimento de implicações sociais e éticas das TIC;

- A capacidade de uso de software utilitário;

- A capacidade de uso e avaliação de software educativo;

- A capacidade de uso de TIC em situações de ensino e aprendizagem.

Dado o vasto número de recursos tecnológicos e as possíveis situações de aplicação, podemos encontrar diferentes papéis que o professor pode desempenhar nos novos cenários que encontra (GISBERT, 2002): consultores de informação, colaboradores em grupo, trabalhadores solitários, facilitadores da aprendizagem, dinamizador de cursos de materiais e supervisores académicos. Apresentamos, no Quadro 2, alguns exemplos de cada um dos papéis que os professores podem desempenhar. 


\begin{tabular}{|c|c|}
\hline Papéis & Descrição \\
\hline $\begin{array}{l}\text { Consultores de } \\
\text { informação }\end{array}$ & $\begin{array}{l}\text { - Pesquisador de materiais e recursos para formação; } \\
\text { - Suporte a alunos para acesso à informação; } \\
\text { - Utilizadores experientes das ferramentas tecnológicas para } \\
\text { pesquisa e recuperação de informação. }\end{array}$ \\
\hline Colaboradores em grupo & $\begin{array}{l}\text { - Facilitadores de planejamentos e resolução de problemas } \\
\text { mediante o trabalho colaborativo (em espaços formais e } \\
\text { informais); } \\
\text { - Assumir novas formas de trabalho colaborativo, tendo em } \\
\text { conta uma colaboração que pode ser não presencial com recurso } \\
\text { a espaços virtuais. }\end{array}$ \\
\hline Trabalhadores solitários & $\begin{array}{l}\text { - Possibilidade de realizar teletrabalho; } \\
\text { - Possibilidade de aproveitamento de ferramentas de } \\
\text { comunicação síncrona e assíncrona. }\end{array}$ \\
\hline $\begin{array}{l}\text { Facilitadores de } \\
\text { aprendizagem }\end{array}$ & $\begin{array}{l}\text { - Ser um facilitador de aprendizagem; } \\
\text { - Actuar como fornecedor de recursos; } \\
\text { - Apoiar como pesquisador de informação. }\end{array}$ \\
\hline $\begin{array}{l}\text { Dinamizador de cursos de } \\
\text { materiais }\end{array}$ & $\begin{array}{l}\text { - Criação de materiais dentro do currículo e envolvendo } \\
\text { ambientes tecnológicos; } \\
\text { - Planificação de actividades e ambientes tecnológicos de } \\
\text { formação; } \\
\text { - Facilitadores de mudanças de conteúdos curriculares. }\end{array}$ \\
\hline Supervisores acadêmicos & $\begin{array}{l}\text { - Diagnosticar as dificuldades acadêmicas dos alunos tanto } \\
\text { para sua formação como para superação dos diferentes níveis } \\
\text { educativos; } \\
\text { - Ajudar os alunos a escolher os seus programas de formação em } \\
\text { função das necessidades individuais, acadêmicas e profissionais; } \\
\text { - Acompanhar e supervisionar os alunos dando feedback para } \\
\text { melhorar os cursos e as diferentes actividades de formação. }\end{array}$ \\
\hline
\end{tabular}

Quadro 2 - Papéis e funções a desempenhar pelo professor.

No seu estudo, Ponte e Serrazina (1998) identificaram que a formação inicial dos professores do $1^{\circ}$ ciclo do ensino básico e dos educadores de infância relativamente às tecnologias e ao seu uso educativo, fica francamente abaixo da formação proporcionada aos professores do $2^{\circ}$ e $3^{\circ}$ ciclo do ensino básico e do ensino secundário de matemática e ciências.

Além do problema relacionado com as diferenças na formação inicial de professores no domínio das tecnologias, nem sempre essa formação se concentra na apresentação e promoção das potencialidades pedagógicas, mas sim na aquisição de 
conhecimentos básicos como o processador de texto (PAIVA, 2002). Urge, por isso, reconhecer a necessidade da formação inicial de professores não ignorar a integração das TIC (GOMES, 2007) e que as instituições de ensino superior reforcem a formação no potencial pedagógico (COSTA, 2008).

O referencial de competências TIC em Portugal, identificado por Costa (2008), lista um conjunto de "macro competências do professor" na utilização da tecnologia na educação:

- Detém conhecimento atualizado sobre recursos tecnológicos e seu potencial de utilização educativo;

- Acompanha o desenvolvimento tecnológico no que implica a responsabilidade profissional do professor;

- Executa operações com Hardware e sistemas operativos (usar e instalar programas, resolver problemas comuns com o computador e periféricos, criar e gerir documentos e pastas, observar regras de segurança no respeito pela legalidade, etc.);

- Acede, organiza e sistematiza a informação em formato digital (pesquisa, seleciona e avalia a informação em função de objetivos concretos);

- Executa operações com programas ou sistemas de informação online e/ou off-line;

- Comunica com os outros, individualmente ou em grupo, de forma síncrona e/ou assíncrona através de ferramentas digitais específicas;

- Elabora documentos em formato digital com diferentes finalidades e para diferentes públicos, em contextos diversificados;

- Conhece e utiliza ferramentas digitais como suporte de processos de avaliação e/ou de investigação;

- Utiliza o potencial dos recursos digitais na promoção do seu próprio desenvolvimento profissional, numa perspectiva de aprendizagem ao longo da vida;

- Compreende vantagens e constrangimentos do uso das TIC no processo educativo e o seu potencial transformador do modo como se aprende.

O Sistema de Formação e Certificação de Competências TIC ${ }^{4}$, do Plano Tecnológico da Educação, promoveu que o perfil de professor utilizador de tecnologias assenta no pressuposto da realização de um percurso de aquisição e operacionalização progressiva das competências digitais, que se concretizam numa certificação de 3 níveis:

- Nível 1: certificação de competências digitais: certifica competências básicas que possibilitam a utilização instrumental das TIC no contexto profissional;

- Nível 2: certificação de competências pedagógicas e profissionais com TIC: certifica competências que permitem ao docente a sua utilização como recurso pedagógico no processo de ensino e aprendizagem e no desenvolvimento de estratégias de ensino; 
- Nível 3: certificação de competências avançadas em TIC na educação: certifica conhecimentos que habilitam o docente à sua utilização como recurso pedagógico numa perspectiva de inovação e investigação educacional.

Naturalmente os professores precisam estar progressivamente preparados para o desafio de integrar as tecnologias no ensino, processo que, de acordo com Cabero (2006), leva os professores a passarem por cinco fases na utilização do computador:

(1) Entrada: aprendizagem dos conhecimentos básicos;

(2) Adopção: adopção da tecnologia para apoiar a actividade docente;

(3) Adaptação: integra a tecnologia na prática da sala de aula;

(4) Apropriação: centra-se no trabalho colaborativo baseado em projectos;

(5) Invenção: descobre novos usos e utiliza vários meios.

A investigação tem revelado que o facto de se distribuírem computadores e respectivos periféricos nas escolas não garante, só por si, a sua utilização nem a sua adequada utilização, sendo necessária a existência de estratégias adequadas para que aconteça uma verdadeira aprendizagem apoiada pelas tecnologias (PATROCÍNIO, 2004).

É necessário e urgente que os professores dos diversos graus de ensino façam uma utilização educativa dos computadores. Para tal, é importante que se invista na formação de professores na área da tecnologia, para que eles se consciencializem da importância das tecnologias em contexto educativo. Mas esta formação implica ensinar os professores não a trabalhar, por exemplo, com os computadores, mas sim ajudá-los a adquirir competências de ensino e de aprendizagem pela exploração de actividades que utilizem o computador (NETO, 2010).

As tecnologias, se bem utilizadas, podem oferecer um ambiente de aprendizagem mais rico, indo ao encontro das necessidades dos alunos. Isso, no entanto, requer uma revisão profunda das políticas e métodos de ensino, fazendo actividades pautadas pela inovação (OCDE, 2001; DIAS, 2013).

Deste modo, julgamos que, efetivamente, o maior desafio é a formação de professores ao nível da utilização pedagógica das tecnologias.

\section{Conclusão}

Os recursos tecnológicos lançam vários desafios na educação, nomeadamente, ao nível do acesso à informação, na diversidade de meios, nos tipos de aprendizagem, nos tipos de comunicação e no novo perfil de alunos e professores.

É reconhecido o facto da tecnologia ter um papel fundamental no acesso à informação, permitindo que, quase em qualquer lugar, seja possível consultar documentos digitais sobre várias temáticas reduzindo o mundo e quebrando fronteiras.

Para além disso, importa realçar que os processos de aprendizagem foram alvo de profundas alterações nos contextos onde a tecnologia passou a estar presente colocando, por exemplo, o aluno como criador de conhecimento através de uma maior autonomia no acesso à informação. 
As escolas, os professores e os alunos passaram a ter novas formas de comunicar. Actualmente, a tecnologia coloca a sala de aula nos mais variados ambientes virtuais e possibilita que a "escola" possa assumir novas formas e novos espaços.

Mas a integração da tecnologia na educação só será uma realidade se os professores forem reais actores da mudança e estiverem formados técnica e pedagogicamente.

Aliás os professores são um dos principais factores de sucesso dos projectos de integração da tecnologia.

\section{Referências}

AMANTE, L. Infância, escola e novas tecnologias. In: COSTA, F.; PERALTA, H.; VISEU, S. (Orgs.). As TIC na educação em Portugal, concepções e práticas. Lisboa: Porto Editora, 2007.

BALANSKAT, A.; BLAMIRE, R.; KEFALA, S. The ICT impact report: a review os studies of ICT impact on schools in Europe. European Schoolnet, 2006.

BELTRÁN, J. Estrategias de aprendizagem. In: BELTRAN, J.; GENOVARD, C. (Eds.). Psicología de la instrucción I: Variables y processos básicos. Madrid: Síntesis, 1996.

CABERO, J. Las nuevas tecnologias en la sociedad de la información. In: CABERO, E. J. (Coord.). Nuevas tecnologias aplicadas a la educación. Madrid: McGraw-Hill, 2006. p. 1-19.

COSTA, F.; JORGE, M. Aprender e inovar com TIC em Portugal: Propostas e Desafios. Centro de Competência da Universidade do Minho, 2011.

COSTA, F. Competências TIC: Estudo de Implementação. v. 1. Gabinete de Estatística e Planeamento da Educação (GEPE), 2008.

COUTINHO, C. A investigação em "meios de ensino" entre 1950 e 1980: expectativas e resultados. Universidade do Minho. Instituto de Educação e Psicologia. Centro de Investigação em Educação, 2006.

CRUZ, E. Análise da Integração das TIC no Currículo Nacional do Ensino Básico. 2009. Dissertação (Mestrado em Tecnologias Educativas) - Universidade de Lisboa, Faculdade de Psicologia e Ciências da Educação, 2009.

DAMÁSIO, M. As tecnologias da informação e da comunicação e o processo educativo. Nova Vega, 2007.

DIAS, M. O papel do software educativo na aprendizagem da matemática: um estudo de caso no $1^{\circ}$ Ciclo do Ensino Básico. 2013. Tese (Doutoramento em Educação na Especialidade de Tecnologia Educativa)- Universidade dos Açores, 2013.

FERNANDES, A. Didáctica das TIC. Universidade Católica Portuguesa. Instituto de Ensino e Formação a Distância, 2004.

GISBERT, M. El nuevo rol del professor en entornos tecnológicos, Accion Pedagógica, v. 11, n. 1, p. 48-59, 2002.

GOMES, C. Uso das tecnologias de informação e comunicação na formação inicial de professores: caracterização, implementação e avaliação de um modelo de formação em rede. 2007. Tese (Doutoramento) - Universidade dos Açores, 2007.

LEMOS, M. A utilização das TIC em sala de aula: contributo para melhorar a motivação dos alunos. 2011. Dissertação (Mestrado) - Universidade Católica Portuguesa, 2011. 
LOPES, H. Relatório de resultados do inquérito aos adultos sobre o Plano Tecnológico da Educação. Universidade Católica Portuguesa, 2010.

MAYER, R. Cognition and instruction: Their historic meeting within Educational Psychology. Journal of Educational Psychology, 84 (4), p. 405-412, 1992.

MODERNO, A. Para uma pedagogia audiovisual na escola portuguesa. 1984. Tese (Doutoramento) - Universidade de Aveiro, 1984.

NETO, A. O uso das TIC nas Escolas do 1 Ciclo do Ensino Básico do Distrito de Bragança. 2010. Dissertação (Mestrado em Sistemas de Informação) - Escola Superior de Tecnologia e de Gestão do Instituto Politécnico de Bragança, 2010.

OCDE. Los desafios de las tecnologías de la información en la educación. Organización para la Cooperación y Desarrollo Económicos (OCDE) y Ministerio de Educación, Cultura y Deporte. España, 2001.

OLIVEIRA, J. Psicologia da Educação, Aprendizagem-Aluno. Porto: Legis Editora, 2007.

PAIVA, J. As tecnologias de informação e comunicação: utilização pelos professores. Departamento de Avaliação Prospectiva e Planeamento, Ministério da Educação, 2002.

PATROCÍNIO, J. Tornar-se pessoa e cidadão digital: aprender e formar-se dentro e fora da escola na sociedade tecnológica globalizada. 2004. Tese (Doutoramento) - Universidade Nova de Lisboa, Faculdade de Ciências e Tecnologia, 2004.

PONTE, J.; SERRAZINA, L. As novas tecnologias na formação inicial de professores. Lisboa: DAPP-ME, 1998.

RAMOS, J. Experiências educativas enriquecedoras no âmbito das tecnologias de informação e comunicação em Portugal: contributos para uma reflexão. In: SILVA, R.; SILVA, A. (Orgs.). Educação, aprendizagem e tecnologia: um paradigma para o século XXI. Lisboa: Edições Sílabo, 2005.

RASINEN, A. An Analysis of the Technology Education Curriculum of Six Countries. Journal of Technology Education, v. 15, n. 1, 2003.

SERRA, A. Motivação e aprendizagem. Porto: Afrontamento, 1986.

SILVA, A. Ensinar e aprender com as tecnologias: Um estudo sobre as atitudes, formação, condições de equipamento e utilização nas escolas do $1^{\circ}$ Ciclo do Ensino Básico do Concelho de Cabeceiras de Basto. 2004. Dissertação (Mestrado em Formação Psicológica de Professores)

- Universidade do Minho, 2004.

SOUZA, R. Uma proposta Construtivista para a Utilização de Tecnologias na Educação. In: SILVA, R.; SILVA, A. (Orgs.). Educação, aprendizagem e tecnologia. Lisboa: Edições Sílabo, 2005.

SPRINTHALL, N.; SPRINTHALL, R. Psicologia educacional: uma abordagem desenvolvimentista. Lisboa: McGraw-Hill, 1993.

TEODORO, V. Educação e computadores. Secção Ciências da Educação, Faculdade de Ciências e Tecnologia, Universidade Nova de Lisboa, 2008.

UNESCO. Integrating ICT into Education. A Collective Case Study of Six Asian Countries. UNESCO Asia and Pacific Regional Bureau for Education. Bangkok, Thailand, 2004. 


\section{Notas}

${ }^{1}$ Organização para a Cooperação e Desenvolvimento Económico. Disponível em: <http://www.oecd.org/>. Acesso em: 12 ago. 2014.

${ }^{2}$ Programme for International Student Assessment. Disponível em: <http://www.oecd.org/pisa/>. Acesso em: 12 ago. 2014.

${ }^{3}$ Indonésia, Malásia, Filipas, Singapura, Coreia do Sul e Tailândia.

${ }^{4}$ Portaria n. $731 / 2009$

* Pós-doutorando na área de Educação pela Universidade do Estado do Rio Grande do Norte, Pau dos ferros, Rio Grande do Norte, Brasil.

\section{Correspondência}

Luis Miguel Dias Caetano - Universidade do Estado do Rio Grande do Norte, Campus Avançado Profa. Maria Elisa de A. Maia (CAMEAM). BR405, KM 3, Arizona, CEP: 59900-000 - Pau dos Ferros, Rio Grande do Norte - Brasil.

E-mail: migueldias.uern@gmail.com

Recebido em 27 de março de 2015

Aprovado em 02 de abril de 2015 